\title{
Location of the narrowest area of the pharynx regarding body mass index and obstructive sleep apnoea severity
}

\author{
M. Krasny ${ }^{1}$, J. Wysocki2, 3 , M. Prus ${ }^{3}$, K. Niemczyk ${ }^{3}$ \\ ${ }^{1}$ Department of Orthodontics, Warsaw Medical University, Warsaw, Poland \\ ${ }^{2}$ Department of Dietetics and Food Evaluation, Institute of Health, Siedlce University of Natural Sciences \\ and Humanities, Siedlce, Poland \\ ${ }^{3}$ Department and Clinic of Otolaryngology, Warsaw Medical University, Warsaw, Poland \\ [Received: 2 February 2017; Accepted: 9 February 2017]
}

\begin{abstract}
Background: Among authors studying morphological determinants of the obstructive sleep apnoea (OSA) controversies exist on the location of the narrowest area within the pharynx, critical for development of obstruction. Those disagreements primarily revolve around differences between obese and nonobese OSA patients. Determination whether the location and size of the narrowest area within the pharynx differentiates the obese and nonobese OSA patients.

Materials and methods: A population of 55 subjects was investigated after being diagnosed with OSA in the Polysomnography Laboratory of the Department and Clinic of Otolaryngology in the Medical University of Warsaw, Poland. Additionally a head computed tomography (CT) was performed in all the subjects. The CT images were used to do several crucial measurements which described the geometry of the facial skeleton as well as soft tissues of the head. The obtained results were correlated with apnoea-hypopnoea index (AHI) and body mass index (BMI) values. The data were statistically analysed.

Results: The distance between the hard palate and posterior pharyngeal wall parallel to the horizontal plane as well as the shortest distance between the soft palate and posterior pharyngeal wall significantly differentiated patients in the subgroups by AHI but not by BMI.

Conclusions: Pharyngeal obstruction at the level of the hard and soft palate differentiates patients with severe OSA from patients with mild and moderate OSA regardless of BMI. (Folia Morphol 2017; 76, 3: 491-500)
\end{abstract}

Key words: obstructive sleep apnoea, pharynx, computed tomography

\section{INTRODUCTION}

Severity of obstructive sleep apnoea (OSA) to certain extent depends on obesity and/or a set of several specific morphological features of the head and neck. The actual reason for OSA severity is being investigated, because in a small group of patients neither obesity nor morphological features could explain severe OSA. There are cases when a single important morphological obstacle in the airway is found - the narrowest place - which leads to OSA.

A determined set of morphological traits is known to predispose subjects to OSA regardless of obesity to

Address for correspondence: Dr. M. Krasny, Department of Orthodontics, ul. Nowogrodzka 59, $02-005$ Warszawa, Poland, tel: +48 225021032 , e-mail: mkrasny@op.pl 
some extent [1]. The traits include micrognathia and retrognathia, distoclusion, macroglossia, hypertrophy of the soft tissue within the oropharyngeal isthmus, low position of the hyoid bone or short and thick neck $[4,8,18,23,24,33]$. The key role in OSA pathogenesis belongs to abnormal pharynx morphology [31]. In particular, obstruction of the oropharynx caused by a massive hypertrophy of the palatopharyngeal arches, palatine tonsils, uvula, and the tongue is significantly related to OSA development and severity $[24,25,32]$.

However, not all the authors agree on the actual role of some morphological traits in manifestation of OSA. The association between apnoea-hypopnoea index (AHI) and the elongated soft palate [24, 25], retrognathia or distoclusion [24] has been questioned. Similarly, while some researchers recognise the role of macroglossia in the ethiopathogenesis of OSA $[24,25]$, others tend to marginalise it $[20,26,30]$.

Many authors pointed out some morphological differences within the pharynx and the facial skeleton between obese and nonobese OSA patients [19, 21, $23,28]$. Compared to patients with habitual snoring who did not suffer from OSA as well as the control group the following traits were often found in nonobese OSA patients: significantly elongated soft palate, decreased antero-posterior dimension of the facial skeleton as well as the oropharynx and nasopharynx and increased distance between the hyoid bone and the base of the mandible $[2,6,14-16,23$, $27,33]$. The abnormalities are proportional to the value of the AHI [11].

Some authors pointed out the airway stenosis at the nasopharyngeal level [33] and/or oropharyngeal level [22, 33] as the most important risk factor for OSA, particularly in nonobese patients [33]. In obese OSA patients the main role was supposed to be played by excessively developed deposit of the parapharyngeal adipose tissue, which corresponded to a significantly larger neck circumference $[3,33]$. Some authors pointed out that in both groups of patients pharyngeal obstruction at the level of the tongue as well as posteriorly from the soft palate may be the most significant $[3,5,9,13,29]$ and the width of the airway at the level of the laryngopharynx was of less importance and did not differentiate obese and slim OSA patients [23]. Whereas, the functional model constructed based on the three-dimensional (3D) pharynx reconstruction and simulations of the airflow resistance indicated that regardless of the obstruction location, the size of the minimal phar- yngeal transverse section as well as the body mass index (BMI) constituted significant predictors of OSA severity [29].

The study objective was to verify whether location and size of the narrowest area within the pharynx depends either on BMI or the OSA severity.

\section{MATERIALS AND METHODS}

Data for this study were selected from the database, regarding their completeness, i.e. the patient's age, gender, primary diagnosis and comorbidities. The population of 55 patients ( 13 females and 42 males) aged 23-67 (mean \pm standard deviation: $46.4 \pm 10.43$ years) was investigated, previously diagnosed with OSA in the Polysomnographic Laboratory, Department and Clinic of Otolaryngology, Warsaw Medical University, Warsaw, Poland. The patients were qualified for imaging in the order of coming to pick up the polysomnography (PSG) results.

The Local Bioethics Committee approved the study protocol and all the patients declared their consent to participate in the study in writing.

Standardised attended 14-channel overnight laboratory PSG was performed (Grass, US). Sleep stages were manually scored in 30-s epochs using standard AASM 2005 criteria. The AHI was computed and manually revised. The OSA severity was classified based on the $\mathrm{AHI}$ and $\mathrm{SO}_{2}$ nadir. Fourteen-channel PSG covered 6 EEG channels (F3-M2, C3-M2, 01-M2, F4-M1, C4-M1, O2-M1), EOG (E1-M2, E2-M2, E1-Fpz, E2-Fpz) EMG (CHIN1-CHIN2, anterior tibial muscle of left leg LAT1-LAT2 and right leg RAT1-RAT2), ECG, thermistor, microphone, blood saturation, chest and abdomen movements, body position. Automatic sleep analysis performed first by a computer programme was then verified (manually revised), especially regarding sleep stages coding (N1, N2, N3, REM, Awake) and apnoea/ hypopnea episodes classification (central, obstructive, mixed), because of many mistakes appearing after the automatic analysis. The statistical tests used in the study were non-parametric because the assumption of the normal distribution of most variables has not been met (tested with the Shapiro-Wilk test).

All the patients had computed tomography (CT) imaging performed with the 3D Accuitomo (J Morita Mfg Corp, Kyoto, Japan). The manufacturer delivered software that was used to measure several selected parameters describing geometry of the facial skeleton and soft tissues of the head in the CT images (Figs. 1-3). 


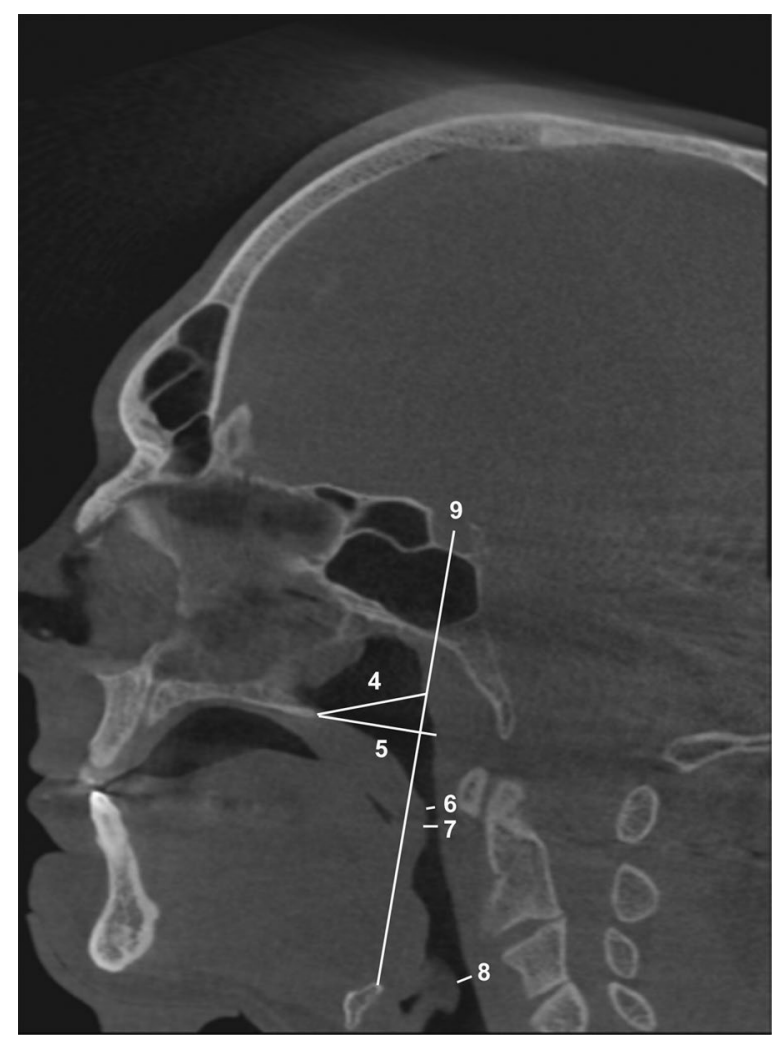

Figure 1. Measurement scheme of linear parameters 4-9.

The examination was performed when patients were awake, in a sitting position with their breathing withheld during the expiratory phase with the head fixed to provide the Frankfurt horizontal plane. The examination was carried out with the following settings: 360 degree scan angle, $\mathrm{X}$-ray beam, conic, pulsed, $110 \mathrm{kV}, 100 \mathrm{~mA} / \mathrm{scan}$, effective exposure time: $18 \mathrm{~s}$, screening field: $17 \times 23 \mathrm{~cm}$, effective radiation dose: range 96.9-105.3 microsievert $[\mu \mathrm{Sv}]$, spatial resolution: $0.3 \mathrm{~mm}$ in $\mathrm{x}, \mathrm{y}$, and $\mathrm{z}$ directions. Upon completion of the cone beam computed tomography (CBCT) examination, some manipulations can be performed using the software provided by the scanner manufacturer. The raw image (raw data) were reconstructed to enable visualisation of 3D reconstruction and multiple planar cross-sections. These 2D images of the pharynx can be examined from any direction. The most commonly used are sagittal, coronal and axial

The obtained results were compared within groups distinguished according to the $\mathrm{AHI}$ value (mild + moderate apnoea vs. severe apnoea) and the BMI (normal body mass + overweight vs. obesity). Patients

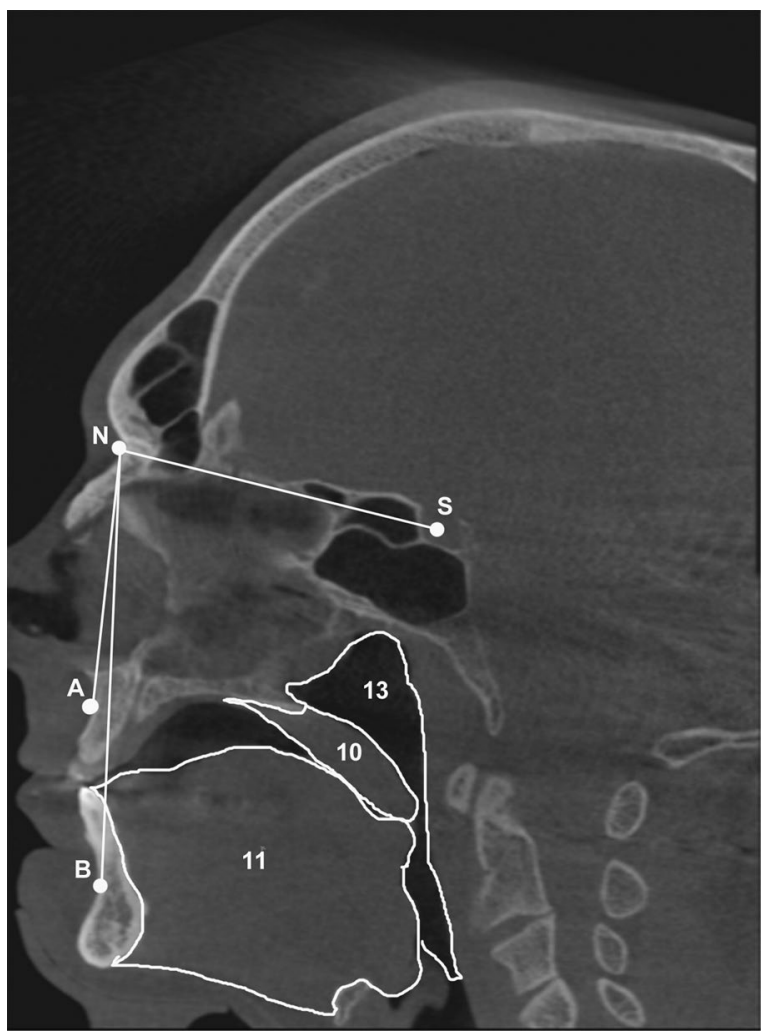

Figure 2. Angular and surface measurement scheme; $N$ (nasion) crossing of the frontonasal and internasal suture; $A$ (subspinale) the deepest depression on anterior maxillary border; $\mathrm{B}$ (submentale) — the deepest depression on anterior mandibular border; 10 — soft palate surface; 11 - surface of the tongue; 12 - nasopharynx surface.

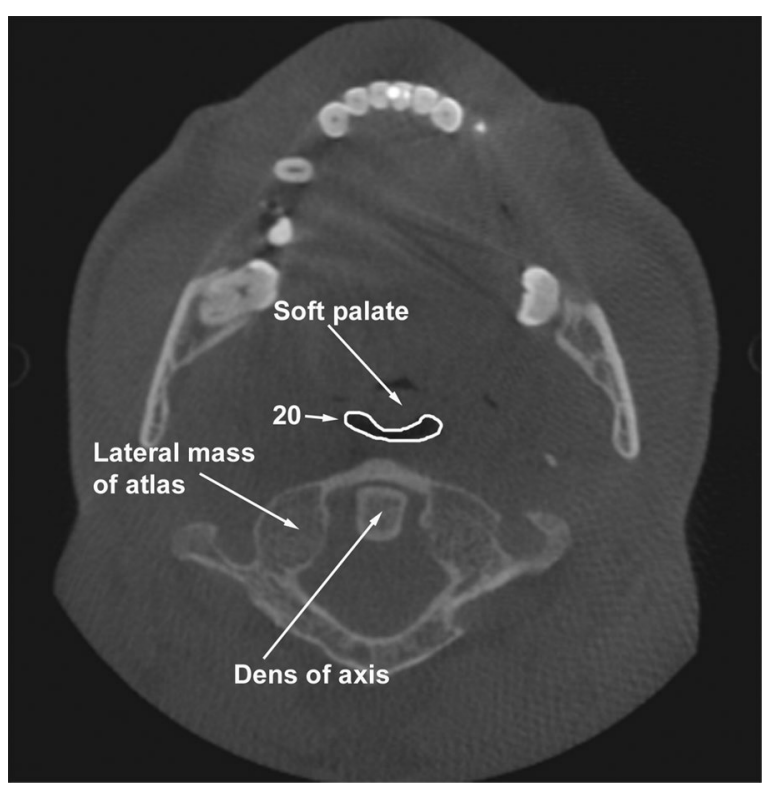

Figure 3. An example surface of the transverse section of the pharynx at the level of the closest contact of the soft palate with the posterior pharyngeal wall (parameter 20). 
with $\mathrm{AHI} 5 \leq \mathrm{AHI}<30$ were classified as mild + moderate OSA; patients with $\mathrm{AHI} \geq 30$ were included into group of severe OSA. Patients with BMI < 30 were classified as normal + overweight, patients with BMI $\geq 30$ were classified as obese.

\section{Statistical analysis}

The statistical analysis employed STATISTICA 10. The Shapiro-Wilk test was used to analyse the conformity of the distribution of the obtained variables to a normal distribution. After the descriptive statistics were calculated the significance of observed differences between the mean values in the groups distinguished by gender and $\mathrm{AHI}$ was tested. The significance of differences in variables was investigated with the use of the Mann-Whitney $U$ test. The significance of correlations between variables was identified with the use of the Spearman's rank correlation coefficient and the contribution of individual independent variables in determination of the $\mathrm{AHI}$ as a dependent variable - with the use of stepwise regression. The stepwise regression was based on regression model and one step procedure (one variable - one step), where all the analysed variables (predictors) were entered at the beginning and with every step subsequent redundant predictors are removed from the model.

\section{RESULTS}

The distance between the hard and soft palate and posterior pharyngeal wall parallel to the horizontal plane was the shortest one among distances measured in the sagittal plane. The shortest distance between the hard palate and the posterior pharyngeal wall, the distance between the hard palate and posterior pharyngeal wall parallel to the horizontal plane, the shortest distance between the soft palate and posterior pharyngeal wall, the shortest distance between the tongue and posterior pharyngeal wall, as well as the shortest distance between epiglottis and posterior pharyngeal wall were smaller in the severe OSA group vs. the mild + moderate OSA group, and in the obese group vs. the overweight group (Tables 1, 2). The surface of the soft palate as well as the total of the soft palate and tongue were greater in the severe OSA group. However, surface of the tongue alone was smaller in this group compared to the mild + moderate OSA group. The distance between the Sella point and hyoid bone and the pharyngeal surface were greater in severe OSA than in mild + moderate OSA group.
The surface of the soft palate, the tongue and both surfaces jointly and the surface of the pharynx were smaller in the obesity group vs. the overweight group.

Several statistically significant correlations were found but only some of them were strong. The significant and close correlations were listed below: the $\mathrm{AHI}$ with $\mathrm{SO}_{2}$ nadir $(-0.66)$; the shortest distance between the hard palate and posterior pharyngeal wall with the distance between the hard palate and posterior pharyngeal wall parallel to the horizontal plane (0.6); the distance between the soft palate and posterior pharyngeal wall with the surface of the transverse section of the pharynx at the level of the soft palate $(0.73)$; the distance between the tongue and posterior pharyngeal wall with the shortest distance between the epiglottis and posterior pharyngeal wall (0.71) and with the surface of the transverse section of the pharynx at the level of the tongue (0.75); the shortest distance between the epiglottis and posterior pharyngeal wall with the surface of the transverse section of the pharynx at the level of the epiglottis (0.77); the distance between the Sella point and hyoid bone with the surface of the tongue (0.75) and with the total surface of the tongue and palate (0.6); the surface of the transverse section of the pharynx at the level of the tongue with the surface of the transverse section of the pharynx at the level of the epiglottis (0.83).

There were three parameters which significantly differentiated patients in the groups by AHI but not by BMI: the distance between the hard palate and posterior pharyngeal wall parallel to the horizontal plane, the shortest distance between soft palate and posterior pharyngeal wall as well as the transverse of the pharynx at the level of the posterior nasal spine. The results of statistical analysis suggested that the measured parameters were independent of obesity and crucial for pharyngeal obstruction in OSA patients

The transverse of the pharynx at the level of the posterior nasal spine significantly differentiated patients in the groups by gender and $\mathrm{AHI}$, but not BMI (Tables 1, 3). Moreover, there was a slight, yet significant correlation ( $r=0.35)$ between this surface and the value of the AHI. Whereas, transverse section of the pharynx at the level of the soft palate significantly differentiated patients in the groups by BMI only (Table 2).

The stepwise regression analysis demonstrated that only the BMI and distance between the hard palate and the posterior pharyngeal wall parallel to 
Table 1. Results of calculations of morphometric and polysomnographic parameters jointly and in subgroups by apnoea-hypopnoea index (AHI)

\begin{tabular}{|c|c|c|c|c|c|c|c|}
\hline \multirow[t]{2}{*}{ Parameter } & \multicolumn{2}{|c|}{$\begin{array}{c}5 \leq \mathrm{AHI}<30 \\
(15.28 \pm 8.58) \\
n=26\end{array}$} & \multicolumn{2}{|c|}{$\begin{array}{c}30<\mathrm{AHI} \\
(58.85 \pm 23.58) \\
\mathrm{n}=29\end{array}$} & \multicolumn{2}{|c|}{$\begin{array}{c}\text { Total } \\
(38.25 \pm 28.31) \\
n=55\end{array}$} & \multirow{2}{*}{$\begin{array}{c}\text { Mann-Whitney } \\
\text { test } \\
\text { p } \\
\end{array}$} \\
\hline & Mean & SD & Mean & SD & Mean & SD & \\
\hline $\mathrm{SO}_{2}$ nadir & 84.08 & 9.34 & 75.86 & 9.19 & 79.75 & 10.13 & 0.0000 \\
\hline $\begin{array}{l}\text { The shortest distance between the hard } \\
\text { palate and the posterior pharyngeal wall }\end{array}$ & 18.19 & 4.31 & 16.85 & 3.94 & 17.48 & 4.17 & 0.3104 \\
\hline $\begin{array}{l}\text { Hard palate — posterior pharyngeal wall } \\
\text { parallelly to the horizontal plane }\end{array}$ & 22.95 & 3.51 & 19.69 & 4.33 & 21.23 & 4.29 & 0.0049 \\
\hline $\begin{array}{l}\text { Soft palate — posterior pharyngeal wall } \\
\text { — the shortest distance }\end{array}$ & 6.57 & 2.89 & 5.02 & 2.08 & 5.75 & 2.61 & 0.0258 \\
\hline $\begin{array}{l}\text { Tongue — posterior pharyngeal wall } \\
\text { - the shortest distance }\end{array}$ & 12.18 & 4.28 & 10.88 & 4.58 & 11.50 & 4.49 & 0.1989 \\
\hline $\begin{array}{l}\text { Epiglottis - posterior pharyngeal wall } \\
\text { — the shortest distance }\end{array}$ & 10.71 & 3.51 & 10.40 & 5.05 & 10.55 & 4.39 & 0.5193 \\
\hline Sella - hyoid bone & 109.02 & 8.91 & 111.36 & 9.64 & 110.17 & 9.35 & 0.3352 \\
\hline The surface of the soft palate & 364.23 & 99.98 & 373.25 & 62.33 & 369.09 & 81.68 & 0.8564 \\
\hline The surface of the tongue & 3073.10 & 392.90 & 2895.72 & 463.70 & 2977.59 & 441.41 & 0.2341 \\
\hline The total surface of the tongue and palate & 3478.74 & 480.29 & 3389.34 & 484.12 & 3431.60 & 484.37 & 0.5085 \\
\hline The surface of the pharynx & 658.26 & 205.93 & 567.73 & 163.76 & 610.53 & 190.34 & 0.0840 \\
\hline SNA & 81.63 & 3.92 & 80.59 & 4.71 & 81.08 & 4.39 & 0.4959 \\
\hline SNB & 77.74 & 4.58 & 78.15 & 3.97 & 77.95 & 4.28 & 0.6629 \\
\hline ANB & 4.01 & 3.30 & 2.64 & 3.99 & 3.30 & 3.74 & 0.2586 \\
\hline $\begin{array}{l}\text { The surface of the transverse section of } \\
\text { the pharynx at the level of the posterior } \\
\text { nasal spine }\end{array}$ & 539.20 & 118.87 & 460.49 & 141.98 & 497.70 & 137.31 & 0.0205 \\
\hline $\begin{array}{l}\text { The surface of the transverse section } \\
\text { of the pharynx at the level of the tongue }\end{array}$ & 368.45 & 183.86 & 311.16 & 172.31 & 338.25 & 180. 15 & 0.1604 \\
\hline $\begin{array}{l}\text { The surface of the transverse section } \\
\text { of the pharynx at the level of the epiglottis }\end{array}$ & 390.94 & 186.82 & 354.10 & 191.87 & 371.52 & 190.39 & 0.3104 \\
\hline $\begin{array}{l}\text { The surface of the transverse section } \\
\text { of the pharynx at the level of the soft palate }\end{array}$ & 189.32 & 120.78 & 141.72 & 84.87 & 164.22 & 106.11 & 0.1041 \\
\hline Body mass index & 27.92 & 2.04 & 31.56 & 3.82 & 29.83 & 3.63 & 0.0001 \\
\hline
\end{tabular}

ANB — angle between the lines: AN and BN; SNA — angle between the lines: SN and NA; S (sella) — geometrical middle point of sella; SNB — angle between the lines: SN and NB SD - standard deviation

the horizontal plane determined the value of the $\mathrm{AHI}$ being a dependent variable in a statistically significant manner. Both the independent variables were responsible for the total of $0.34 \%$ of the AHI variability range (Tables 4 and 5).

\section{DISCUSSION}

Demonstration that the distance between the soft palate and the posterior pharyngeal wall is significantly shorter in patients with severe OSA confirmed an observation about the role of the soft palate in OSA pathogenesis. A clinical trial in 306 subjects with cephalometric evaluation performed in two planes demonstrated that OSA patients showed significantly longer vertical dimension of the pharynx, thicker soft palate, and shorter transverse dimensions of the pharynx at different levels. OSA severity expressed by $A H I$ significantly correlated with greater thickness of the soft palate and increased BMI [7]. OSA patients seemed to show an interesting characteristic of increased deposit of the parapharyngeal adipose tissue regardless, to some extent, of the overall adiposity [18]. This study found the surface of the soft palate, tongue section as well as the surface of both 
Table 2. Matrix of Spearman's rank correlation coefficients among individual variables. Numbers allocated to variables correspond to the description in table

\begin{tabular}{|c|c|c|c|c|c|c|c|c|c|c|c|c|c|c|c|c|c|c|c|c|}
\hline & 2 & 3 & 4 & 5 & 6 & 7 & 8 & 9 & 10 & 1 & 12 & 3 & 14 & 15 & 16 & 7 & 18 & 19 & 20 & 21 \\
\hline 2 & & ; & - & - & - & & 6 & 0.23 & 0.03 & 9 & 10 & & 4 & & & 35 & 26 & 17 & & 59 \\
\hline 3 & & & 0.14 & & & 6 & & & & & & & & & & 32 & 28 & & 3 & 40 \\
\hline 4 & & 14 & 1. & O & -0.04 & -0.05 & -0.12 & -0.08 & $\cap \cap 4$ & 0.02 & 0.08 & 0.04 & -0.03 & -0.13 & 0.05 & 0.31 & -0.03 & -0.02 & -0.03 & -0.1 \\
\hline 5 & & 24 & 0. & 1.00 & 0.17 & .13 & -0.20 & -0.12 & 0.10 & 0.03 & & 0.03 & .02 & -0.24 & 0.16 & 0.47 & -0.04 & -0.03 & 05 & -0.12 \\
\hline 6 & .31 & 0.32 & 0.04 & 0.17 & 1.00 & 0.4 & 0.43 & -0.13 & 32 & 06 & 0.04 & 57 & .30 & -0.04 & 14 & 0.34 & .40 & 0.36 & 73 & -0.08 \\
\hline 7 & ).16 & 16 & 5 & -0.13 & 0 & 1.00 & 0. & 0.02 & 8 & 0.08 & & 0.62 & 23 & 14 & -0.30 & 1 & 75 & 70 & 44 & -0 \\
\hline 8 & 1.06 & 0.11 & 12 & -0.20 & 0.43 & 0.7 & 1.00 & 0.20 & $-0,22$ & 0.20 & 0. & 0.55 & -0.29 & 0.08 & -0.29 & 0.01 & 0.64 & 0.77 & 35 & -0.16 \\
\hline 9 & 0.23 & .25 & -0.08 & .12 & -0.13 & 0.02 & 0.20 & .00 & 0.39 & 0.75 & 60 & 0.27 & 0.20 & 0.44 & .22 & 28 & -0.01 & .12 & 12 & -0.17 \\
\hline 1 & 0.0 & 0.15 & 0.04 & 0.10 & -0.32 & -0.18 & -0.22 & 0.39 & 1.00 & 0.37 & & -0.12 & 0.18 & 0.21 & -0.05 & -0.39 & -0.28 & -0.17 & -0.41 & -0.0 \\
\hline 11 & .09 & -0.20 & 0.02 & 0.0 & 0.06 & 0.08 & 0.20 & 0.75 & 0.3 & 1.00 & 0. & 0.35 & 0.25 & 0.42 & -0.01 & -0.27 & 0.02 & 0.19 & 2 & -0 \\
\hline 12 & 0.00 & 0.15 & 0.08 & 0.15 & 0.04 & 0.04 & 0.19 & 0.60 & 0.57 & 0.96 & 1.00 & 0.13 & 0.27 & 0.37 & -0.05 & -0.31 & -0.05 & 0.12 & -0.14 & -0.2 \\
\hline 13 & 0.20 & 16 & 0.04 & 0.03 & 057 & 0.62 & 0.55 & 0.27 & ? & 0.35 & & 1.00 & -0.16 & 0.03 & -0.11 & 0.31 & 0.64 & 0. & 0.57 & -0.0 \\
\hline 14 & 14 & -0.03 & -0.03 & -0.02 & -0.30 & -0.23 & -0.29 & 0.20 & 0.18 & 0.25 & 0.27 & -0.16 & 1.00 & 0.60 & 0.36 & -0.07 & -0.32 & -0.22 & -0.34 & -0.1 \\
\hline 15 & .03 & -0.17 & -0.13 & 0.24 & -0.04 & 0.14 & 0.08 & 0.44 & 0.21 & 0.42 & 0.37 & 0.03 & 0.60 & 1.00 & -0.45 & -0.25 & -0.08 & 0.02 & -0.16 & -0.2 \\
\hline 16 & 10 & 0.14 & 0.05 & 0.16 & -0.14 & -0.30 & -0.29 & -0.22 & -0.05 & -0.01 & -0 & -0.11 & 0.36 & -0 & 1.00 & 0.17 & -0.22 & -0.14 & -0.11 & 0. \\
\hline 17 & .35 & 0.32 & 0.31 & 0.47 & 0.34 & -0.01 & 0.01 & -0.28 & -0.39 & -0.27 & -0.31 & 0.31 & -0.07 & -0.25 & 0.17 & 1.00 & 0.23 & 0.12 & 0.41 & -0.11 \\
\hline 18 & .26 & 0.28 & 0.03 & 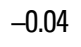 & 0.40 & 0.75 & 0.64 & -0.01 & -0.28 & 0.02 & -0 & 0.64 & -0.32 & -0.08 & -0.22 & 0.23 & 1.00 & 0.83 & 0.64 & $-c$ \\
\hline 19 & .17 & 0.20 & -0.02 & -0.03 & 0.36 & 0.70 & 0.77 & 0.12 & -0.17 & 0.19 & 0.12 & 0.61 & -0.22 & 0.02 & -0.14 & 0.12 & 0.83 & 1.00 & 0.44 & -0.1 \\
\hline 20 & .25 & 0.23 & 0.03 & 0.05 & 0.73 & 0.44 & 0.35 & -0.12 & -0.41 & -0.12 & -0.1 & 0.57 & -0.34 & -0.16 & -0.11 & 0.41 & 0.64 & 0.44 & 1.00 & -0.14 \\
\hline 21 & .59 & 0.40 & -0.15 & -0.12 & -0.08 & -0.16 & -0.16 & -0.17 & -0.06 & -0.15 & -0.20 & -0.06 & -0.15 & -0.28 & 0.15 & -0.11 & -0.18 & -0.18 & -0.14 & 1.00 \\
\hline
\end{tabular}

sections jointly being smaller in the obese group vs. the overweight group. Hence, not the adipose tissue deposits but specific morphological traits of the head and neck seem to condition the more severe or milder OSA. The pharyngeal lumen was found to be the narrowest at the level of the palate; at this level the parapharyngeal space contains mainly pterygoid muscles, blood vessels, and nerves with a small amount of the adipose tissue. The influence of larger accumulation of the adipose tissue in obese subjects could be reflected in measurements at lower levels but it was not determined.

It was not confirmed that the dimension of the retrolingual space was significantly associated with the $\mathrm{AHI}$ as it had been claimed by some authors [3]. We did not find confirmation for the observation that obese patients show a significantly longer tongue with an increased total tongue surface [10, 23, 27].
Similarly, no significant differences were found in terms of basic cephalometric angular parameters (ANB - angle between the lines: AN and BN; SNA angle between the lines: SN and NA; SNB - angle between the lines: $\mathrm{SN}$ and $\mathrm{NB}$ ) between the subgroups by gender, $\mathrm{AHI}$ or $\mathrm{BMI}$, which confirms observations of other authors who analysed the Caucasian population [2]. Whereas in Japanese patients apart from the $\mathrm{BMI}$, the facial skeleton angles are supposed to be the major determinants of the AHI; the dolichofacial morphology as well as reduced SNA and SNB are expected to increase the risk of OSA [14].

The distance between the Sella point and the hyoid bone characterising the vertical position of the hyoid bone was significantly larger in males in the investigated sample but it did not differentiate the subjects by $\mathrm{AHI}$ or BMI. This result did not confirm observations on the lower position of the hyoid bone 
Table 3. Results of calculations of morphometric and polysomnographic parameters jointly and in subgroups by gender

\begin{tabular}{|c|c|c|c|c|c|c|c|}
\hline \multirow[t]{2}{*}{ Parameter } & \multicolumn{2}{|c|}{$\begin{array}{l}\text { Females } \\
(\mathrm{n}=13)\end{array}$} & \multicolumn{2}{|c|}{$\begin{array}{l}\text { Males } \\
(\mathrm{n}=42)\end{array}$} & \multicolumn{2}{|c|}{$\begin{array}{c}\text { Total } \\
\text { (n= 55) }\end{array}$} & \multirow{2}{*}{$\begin{array}{c}\begin{array}{c}\text { Mann-Whitney } \\
\text { test }\end{array} \\
p\end{array}$} \\
\hline & Mean & SD & Mean & SD & Mean & SD & \\
\hline Apnoea-hypopnoea index & 36.95 & 31.47 & 38.66 & 27.24 & 38.25 & 28.31 & 0.5983 \\
\hline $\mathrm{SO}_{2}$ nadir & 80.31 & 12.09 & 79.57 & 9.43 & 79.75 & 10.13 & 0.4747 \\
\hline $\begin{array}{l}\text { The shortest distance between } \\
\text { the hard palate and the posterior } \\
\text { pharyngeal wall }\end{array}$ & 16.18 & 3.26 & 17.88 & 4.34 & 17.48 & 4.17 & 0.1625 \\
\hline $\begin{array}{l}\text { Hard palate - posterior pharyngeal } \\
\text { wall parallelly to the horizontal plane }\end{array}$ & 21.02 & 3.42 & 21.30 & 4.52 & 21.23 & 4.29 & 0.7211 \\
\hline $\begin{array}{l}\text { Soft palate - posterior pharyngeal } \\
\text { wall — the shortest distance }\end{array}$ & 6.77 & 2.37 & 5.44 & 2.60 & 5.75 & 2.61 & 0.0883 \\
\hline $\begin{array}{l}\text { Tongue - posterior pharyngeal } \\
\text { wall — the shortest distance }\end{array}$ & 11.52 & 3.47 & 11.49 & 4.76 & 11.50 & 4.49 & 0.8585 \\
\hline $\begin{array}{l}\text { Epiglottis - posterior pharyngeal } \\
\text { wall — the shortest distance }\end{array}$ & 10.31 & 3.68 & 10.62 & 4.59 & 10.55 & 4.39 & 0.9921 \\
\hline Sella - hyoid bone & 100.37 & 6.37 & 113.35 & 7.83 & 110.17 & 9.35 & 0.0000 \\
\hline The surface of the soft palate & 288.09 & 73.35 & 400.91 & 59.9 & 369.09 & 81.68 & 0.0001 \\
\hline The surface of the tongue & 2589.17 & 430.36 & 3130.18 & 340.70 & 2977.59 & 441.41 & 0.0026 \\
\hline The total surface of the tongue and palate & 2911.14 & 438.35 & 3592.70 & 371.44 & 3431.60 & 484.37 & 0.0000 \\
\hline The surface of the pharynx & 592.01 & 112.12 & 616.26 & 208.36 & 610.53 & 190.34 & 0.8975 \\
\hline SNA & 80.66 & 2.73 & 81.22 & 4.80 & 81.08 & 4.39 & 0.7722 \\
\hline SNB & 75.75 & 3.61 & 78.69 & 4.23 & 77.95 & 4.28 & 0.0374 \\
\hline ANB & 4.92 & 2.57 & 2.76 & 3.91 & 3.30 & 3.74 & 0.0585 \\
\hline $\begin{array}{l}\text { The surface of the transverse section } \\
\text { of the pharynx at the level of the } \\
\text { posterior nasal spine }\end{array}$ & 585.97 & 116.56 & 470.38 & 131.63 & 497.70 & 137.31 & 0.0103 \\
\hline $\begin{array}{l}\text { The surface of the transverse section } \\
\text { of the pharynx at the level of the tongue }\end{array}$ & 326.99 & 127.26 & 341.73 & 193.48 & 338.25 & 180.15 & 0.7891 \\
\hline $\begin{array}{l}\text { The surface of the transverse section } \\
\text { of the pharynx at the level of the epiglottis }\end{array}$ & 335.70 & 142.52 & 382.60 & 201.65 & 371.52 & 190.39 & 0.7588 \\
\hline $\begin{array}{l}\text { The surface of the transverse section } \\
\text { of the pharynx at the level of the soft palate }\end{array}$ & 189.02 & 76.55 & 156.54 & 79.67 & 164.22 & 106.11 & 0.1153 \\
\hline Body mass index & 31.75 & 4.54 & 29.25 & 3.02 & 29.83 & 3.63 & 0.0714 \\
\hline
\end{tabular}

ANB — angle between the lines: AN and BN; SNA — angle between the lines: SN and NA; S (sella) — geometrical middle point of sella; SNB — angle between the lines: SN and NB; SD - standard deviation

in OSA patients compared to healthy volunteers $[6,10,27,33]$. Moreover, the inferior displacement of the hyoid bone in slim OSA patients as well as inferior and anterior displacement in obese subjects were reported by numerous authors [23, 33]. This study did not involve a control group of healthy volunteers or patients with habitual snoring and OSA ruled out. The stepwise regression analysis conducted for the $\mathrm{AHI}$ as a dependent variable did not confirm a significant contribution of the location of the hyoid bone in the model [3, 33].

The surface of the tongue, which was supposed to correlate positively with the distance between the hyoid bone and the base of the mandible [17], did not demonstrate such a relation in the investigated sample. The BMI was not found to correlate with the tongue surface, which indirectly confirmed similar observations on the lack of correlation between the $\mathrm{AHI}$ and the tongue volume [12]. The Spearman's rank correlation coefficient did not confirm a dependence between the BMI and pharynx transverse section claimed by some authors - the decrease of the pharynx transverse section with the growing BMI [6]. All the correlations between the BMI and these parameters were not statistically significant in the presented sample. 
Table 4. Results of calculations of morphometric and polysomnographic parameters jointly and in subgroups by body mass index (BMI)

\begin{tabular}{|c|c|c|c|c|c|c|c|}
\hline \multirow[t]{2}{*}{ Parameter } & \multicolumn{2}{|c|}{$\begin{array}{c}\mathrm{BMI}<30 \\
(\text { mean } 27.73 \pm 1.45) \\
\mathrm{n}=36\end{array}$} & \multicolumn{2}{|c|}{$\begin{array}{c}30<\mathrm{BMI} \\
\text { (mean } 33.83 \pm 3.04) \\
n=19\end{array}$} & \multicolumn{2}{|c|}{$\begin{array}{c}\text { Total } \\
(29.83 . \pm 3.63) \\
n=55\end{array}$} & \multirow{2}{*}{$\begin{array}{c}\begin{array}{c}\text { Mann-Whitney } \\
\text { test }\end{array} \\
\mathbf{p}\end{array}$} \\
\hline & Mean & SD & Mean & SD & Mean & SD & \\
\hline Apnoea-hypopnoea index & 15.28 & 8.58 & 58.85 & 23.58 & 38.25 & 28.31 & 0.0015 \\
\hline $\mathrm{SO}_{2}$ nadir & 83.17 & 5.82 & 73.26 & 12.99 & 79.75 & 10.13 & 0.0043 \\
\hline $\begin{array}{l}\text { The shortest distance between the hard } \\
\text { palate and the posterior pharyngeal wall }\end{array}$ & 18.22 & 3.53 & 16.07 & 4.87 & 17.48 & 4.17 & 0.2399 \\
\hline $\begin{array}{l}\text { Hard palate - posterior pharyngeal wall } \\
\text { parallelly to the horizontal plane }\end{array}$ & 21.82 & 3.77 & 20.13 & 4.93 & 21.23 & 4.29 & 0.2847 \\
\hline $\begin{array}{l}\text { Soft palate — posterior pharyngeal wall } \\
\text { — the shortest distance }\end{array}$ & 6.25 & 2.84 & 4.82 & 1.79 & 5.75 & 2.61 & 0.1022 \\
\hline $\begin{array}{l}\text { Tongue — posterior pharyngeal wall } \\
\text { — the shortest distance }\end{array}$ & 12.13 & 4.67 & 10.29 & 3.85 & 11.50 & 4.49 & 0.2130 \\
\hline $\begin{array}{l}\text { Epiglottis - posterior pharyngeal wall } \\
\text { - the shortest distance }\end{array}$ & 11.17 & 4.36 & 9.37 & 4.20 & 10.55 & 4.39 & 0.2399 \\
\hline Sella - hyoid bone & 110.22 & 9.69 & 110.03 & 8.45 & 110.17 & 9.35 & 0.7678 \\
\hline The surface of the soft palate & 371.47 & 85.33 & 364.84 & 74.52 & 369.09 & 81.68 & 0.8979 \\
\hline The surface of the tongue & 3058.84 & 406.07 & 2832.49 & 464.21 & 2977.59 & 441.41 & 0.1547 \\
\hline The total surface of the tongue and palate & 3500.07 & 479.58 & 3301.88 & 466.55 & 3431.60 & 484.37 & 0.1310 \\
\hline The surface of the pharynx & 641.11 & 207.08 & 552.58 & 136.00 & 610.53 & 190.34 & 0.4093 \\
\hline SNA & 81.18 & 4.97 & 80.88 & 2.92 & 81.08 & 4.39 & 0.9634 \\
\hline SNB & 78.31 & 4.59 & 77.28 & 3.53 & 77.95 & 4.28 & 0.2569 \\
\hline ANB & 3.13 & 3.99 & 3.62 & 3.18 & 3.30 & 3.74 & 0.5979 \\
\hline $\begin{array}{l}\text { The surface of the transverse section } \\
\text { of the pharynx at the level of the posterior } \\
\text { nasal spine }\end{array}$ & 515.07 & 124.25 & 464.79 & 153.85 & 497.70 & 137.31 & 0.4396 \\
\hline $\begin{array}{l}\text { The surface of the transverse section } \\
\text { of the pharynx at the level of the tongue }\end{array}$ & 371.46 & 184.94 & 275.31 & 151.97 & 338.25 & 180.15 & 0.0950 \\
\hline $\begin{array}{l}\text { The surface of the transverse section } \\
\text { of the pharynx at the level of the epiglottis }\end{array}$ & 393.91 & 187.11 & 329.08 & 189.31 & 371.52 & 190.39 & 0.1824 \\
\hline $\begin{array}{l}\text { The surface of the transverse section } \\
\text { of the pharynx at the level of the soft palate }\end{array}$ & 189.15 & 115.40 & 116.98 & 62.86 & 164.22 & 106.11 & 0.0484 \\
\hline
\end{tabular}

ANB — angle between the lines: AN and BN; SNA — angle between the lines: SN and NA; S (sella) — geometrical middle point of sella; SNB — angle between the lines: SN and NB; SD - standard deviation

The analysis results seem to form a coherent whole. Both the linear dimensions and surface dimensions at the level of the nasopharynx significantly differentiated the patients by $\mathrm{AHI}$ and $\mathrm{BMI}$ and one of the parameters significantly correlated with the AHI as the only one apart from the BMI and significantly determined the range of the $\mathrm{AHI}$ as a dependent variable. This is a confirmation for observations according to which the narrowest area, both in patients with habitual snoring and in OSA patients, is the level of the soft palate, with significantly smaller dimensions being typical for OSA patients [13].

Finally, it is worth mentioning that a comparison of the obtained results with the results from other studies is hindered by some methodological differences as some authors included patients with the $\mathrm{AHI}>10$ in the sleep apnoea study groups $[2,25]$. This is one of the reasons why the methodology of treatment qualification as well as OSA treatment outcome presented by various authors are very divergent. Some authors consider patients with the BMI $>27$ as being obese [33], which makes it difficult to compare the obtained results.

\section{CONCLUSIONS}

The narrowest place in the pharynx is located at the level of the soft palate and differentiates patients with severe OSA from patients with mild and moderate OSA regardless of their BMI. 
Table 5. Results of stepwise regression for the apnoea-hypopnoea index (AHI) dependent variable

\begin{tabular}{lcccccc}
\hline & Step +to/-z & $\begin{array}{c}\text { Multiple Spearman } \\
\text { rank test }\end{array}$ & $\begin{array}{c}\text { Multiple } \\
\text { R-squared }\end{array}$ & $\begin{array}{c}\text { Change } \\
\text { of R-squared }\end{array}$ & F & p \\
\hline Variable 21 & 1 & 0.430778 & 0.185570 & 0.185570 & 8.202693 & 0.006936 \\
Variable 5 & 2 & 0.585101 & 0.342343 & 0.156773 & 8.343313 & 0.006599 \\
Variable 13 & 3 & 0.638089 & 0.407157 & 0.064815 & 3.717168 & 0.062242 \\
Variable 4 & 4 & 0.687255 & 0.472319 & 0.065162 & 4.075071 & 0.051707 \\
Variable 19 & 5 & 0.701612 & 0.492259 & 0.019940 & 1.256733 & 0.270613 \\
Variable 16 & 6 & 0.707331 & 0.500318 & 0.008058 & 0.499940 & 0.484808 \\
Variable 6 & 7 & 0.717154 & 0.514310 & 0.013993 & 0.864290 & 0.359962 \\
Variable 11 & 8 & 0.721613 & 0.520726 & 0.006415 & 0.388174 & 0.538130 \\
Variable 8 & 9 & 0.726291 & 0.527499 & 0.006773 & 0.401380 & 0.531519 \\
Variable 14 & 10 & 0.729454 & 0.532103 & 0.004604 & 0.265697 & 0.610428 \\
Variable 15 & 11 & 0.735557 & 0.541044 & 0.008941 & 0.506497 & 0.482997 \\
Variable 7 & 12 & 0.738917 & 0.545998 & 0.004954 & 0.272808 & 0.606052 \\
Variable 20 & 13 & 0.740924 & 0.548968 & 0.002970 & 0.158049 & 0.694473 \\
\hline
\end{tabular}

\section{Acknowledgements}

This research was investigator-sponsored and received no specific grant from any funding agency in the public, commercial, or non-profit sectors.

\section{REFERENCES}

1. Chebbo A, Tfaili A, Ghamande S. Anatomy and physiology of obstructive sleep apnea. Sleep Med Clin. 2013; 8(4): 425-431, doi:10.1016/j.jsmc.2013.07.016.

2. Cuccia AM, Campisi G, Cannavale R, et al. Obesity and craniofacial variables in subjects with obstructive sleep apnea syndrome: comparisons of cephalometric values. Head Face Med. 2007; 3: 41-50, doi: 10.1186/1746-160X3-41, indexed in Pubmed: 18154686.

3. Davies RJO, Stradling JR. The relationship between neck circumference, radiographic pharangeal anatomy, and the obstructive sleep apnoea syndrome. Eur Respir J. 1990; 3: 509-514.

4. Dreher A, de la Chaux R, Klemens C, et al. Correlation between otorhinolaryngologic evaluation and severity of obstructive sleep apnea syndrome in snorers. Arch Otolaryngol Head Neck Surg. 2005; 131(2): 95-98, doi: 10.1001/ archotol.131.2.95, indexed in Pubmed: 15723938.

5. Fajdiga I. Snoring imaging: could Bernoulli explain it all? Chest. 2005; 128(2): 896-901, doi: 10.1378/ chest.128.2.896, indexed in Pubmed: 16100183.

6. Finkelstein $\mathrm{Y}$, Wexler $\mathrm{D}$, Horowitz $\mathrm{E}$, et al. Frontal and lateral cephalometry in patients with sleep-disordered breathing. Laryngoscope. 2001; 111(4): 634-641, doi: 10.1097/00005537-200104000-00014, indexed in Pubmed: 11359132.

7. Finkelstein $Y$, Wolf $L$, Nachmani $A$, et al. Velopharyngeal anatomy in patients with obstructive sleep apnea versus normal subjects. J Oral Maxillofac Surg. 2014; 72(7): 1350-1372, doi: 10.1016/j.joms.2013.12.006, indexed in Pubmed: 24485981.
8. Friedman M, Ibrahim H, Bass L. Clinical staging for sleep-disordered breathing. Otolaryngol Head Neck Surg. 2002; 127(1): 13-21, doi:10.1067/ mhn.2002.126477, indexed in Pubmed: 12161725.

9. Haponik EF, Smith PL, Bohlman ME, et al. Computerized tomography in obstructive sleep apnea. Correlation of airway size with physiology during sleep and wakefulness. Am Rev Respir Dis. 1983; 127(2): 221-226, doi: 10.1164/ arrd.1983.127.2.221, indexed in Pubmed: 6830039.

10. Hochban W, Brandenburg U. Morphology of the viscerocranium in obstructive sleep apnoea syndrome-cephalometric evaluation of 400 patients. J Craniomaxillofac Surg. 1994; 22(4): 205-213, indexed in Pubmed: 7962567.

11. Hou HM, Hägg U, Sam K, et al. Dentofacial characteristics of Chinese obstructive sleep apnea patients in relation to obesity and severity. Angle Orthod. 2006; 76(6): 962-969, doi: 10.2319/081005-273, indexed in Pubmed: 17090158.

12. lida-Kondo C, Yoshino N, Kurabayashi T, et al. Comparison of tongue volume/oral cavity volume ratio between obstructive sleep apnea syndrome patients and normal adults using magnetic resonance imaging. J Med Dent Sci. 2006; 53(2): 119-126, indexed in Pubmed: 16913573.

13. Koren A, Groselj LD, Fajdiga I. CT comparison of primary snoring and obstructive sleep apnea syndrome: role of pharyngeal narrowing ratio and soft palatetongue contact in awake patient. Eur Arch Otorhinolaryngol. 2009; 266(5): 727-734, doi: 10.1007/ s00405-008-0800-z, indexed in Pubmed:18797909.

14. Kubota $Y$, Nakayama $H$, Takada $T$, et al. Facial axis angle as a risk factor for obstructive sleep apnea. Intern Med. 2005; 44(8): 805-810, indexed in Pubmed: 16157977.

15. Kushida CA, Efron B, Guilleminault C. A predictive morphometric model for the obstructive sleep ap- 
nea syndrome. Ann Intern Med. 1997; 127(8): 581-587, indexed in Pubmed: 9341055.

16. Li KK, Kushida C, Powell NB, et al. Obstructive sleep apnea syndrome: a comparison between Far-East Asian and white men. Laryngoscope. 2000; 110(10 Pt 1): 1689-1693, doi: 10.1097/00005537-200010000-00022, indexed in Pubmed: 11037826.

17. Maltais F, Carrier G, Cormier Y, et al. Cephalometric measurements in snorers, non-snorers, and patients with sleep apnoea. Thorax. 1991; 46(6): 419-423, indexed in Pubmed: 1858079.

18. Mortimore IL, Marshall I, Wraith PK, et al. Neck and total body fat deposition in nonobese and obese patients with sleep apnea compared with that in control subjects. Am J Respir Crit Care Med. 1998; 157(1): 280-283, doi: 10.1164/ajrccm.157.1.9703018, indexed in Pubmed: 9445310

19. Nelson S, Hans M. Contribution of craniofacial risk factors in increasing apneic activity among obese and nonobese habitual snorers. Chest. 1997; 111(1): 154-162, indexed in Pubmed: 8996010.

20. Okubo M, Suzuki M, Horiuchi A, et al. Morphologic analyses of mandible and upper airway soft tissue by MRI of patients with obstructive sleep apnea hypopnea syndrome. Sleep. 2006; 29(7): 909-915, indexed in Pubmed: 16895258.

21. Pahkala R, Seppä J, Ikonen A, et al. The impact of pharyngeal fat tissue on the pathogenesis of obstructive sleep apnea. Sleep Breath. 2014; 18(2): 275-282, doi: 10.1007/ s11325-013-0878-4, indexed in Pubmed: 23877124.

22. Rama AN, Tekwani SH, Kushida CA. Sites of obstruction in obstructive sleep apnea. Chest. 2002; 122(4): 1139-1147, indexed in Pubmed: 12377834.

23. Sakakibara H, Tong M, Matsushita K, et al. Cephalometric abnormalities in non-obese and obese patients with obstructive sleep apnoea. Eur Respir J. 1999; 13(2): 403-410, indexed in Pubmed: 10065689.

24. Schellenberg JB, Maislin G, Schwab RJ. Physical findings and the risk for obstructive sleep apnea. The importance of oropharyngeal structures. Am J Respir Crit
Care Med. 2000; 162(2 Pt 1): 740-748, doi: 10.1164/ ajrccm.162.2.9908123, indexed in Pubmed: 10934114.

25. Schwab RJ. Imaging for the snoring and sleep apnea patient. Dent Clin North Am. 2001; 45(4): 759-796, indexed in Pubmed: 11699240.

26. Shigeta $Y$, Ogawa $T$, Ando $E$, et al. Influence of tongue/ mandible volume ratio on oropharyngeal airway in Japanese male patients with obstructive sleep apnea. Oral Surg Oral Med Oral Pathol Oral Radiol Endod. 2011; 111(2): 239-243, doi: 10.1016/j.tripleo.2010.10.013, indexed in Pubmed:21237441.

27. Tangugsorn V, Skatvedt O, Krogstad O, et al. Obstructive sleep apnoea: a cephalometric study. Part I. Cervicocraniofacial skeletal morphology. Eur J Orthodont. 1995; 17(1): 45-56, doi: 10.1093/ejo/17.1.45.

28. Tsuchiya M, Lowe AA, Pae EK, et al. Obstructive sleep apnea subtypes by cluster analysis. Am J Orthod Dentofacial Orthop. 1992; 101(6): 533-542, doi:10.1016/08895406(92)70128-W, indexed in Pubmed: 1598893.

29. Vos W, De Backer J, Devolder A, et al. Correlation between severity of sleep apnea and upper airway morphology based on advanced anatomical and functional imaging. J Biomech. 2007; 40(10): 2207-2213, doi: 10.1016/j. jbiomech.2006.10.024, indexed in Pubmed: 17178125.

30. Welch KC, Foster GD, Ritter CT, et al. A novel volumetric magnetic resonance imaging paradigm to study upper airway anatomy. Sleep. 2002; 25(5): 532-542, indexed in Pubmed: 12150320.

31. Wilhelm CP, deShazo RD, Tamanna S, et al. The nose, upper airway, and obstructive sleep apnea. Ann Allergy Asthma Immunol. 2015; 115(2): 96-102, doi: 10.1016/j. anai.2015.06.011, indexed in Pubmed: 26250769.

32. Yagi $H$, Nakata $S$, Tsuge $H$, et al. Morphological examination of upper airway in obstructive sleep apnea. Auris Nasus Larynx. 2009; 36(4): 444-449, doi: 10.1016/j. anl.2008.11.003, indexed in Pubmed: 19097716.

33. Yu X, Fujimoto K, Urushibata K, et al. Cephalometric analysis in obese and nonobese patients with obstructive sleep apnea syndrome. Chest. 2003; 124(1): 212-218, indexed in Pubmed: 12853525. 